\title{
Outcomes of patients with large middle cerebral artery infarct treated with and without intravenous thrombolysis
}

\author{
Pornpatr A. Dharmasaroja, Sombat Muengtaweepongsa ${ }^{1}$ \\ Department of Internal Medicine, Stroke and Neurodegenerative Diseases Research Unit, Faculty of Medicine, Thammasat University, \\ ${ }^{1}$ Department of Internal Medicine, Faculty of Medicine, Thammasat University, Pathumthani 12120, Thailand
}

\begin{abstract}
Background: Many thrombolytic studies showed that severe stroke was associated with death and having symptomatic intracerebral hemorrhage and inversely related to a favorable outcome. Aims: The purpose of this study is to compare the outcomes of patients with acute large middle cerebral artery (MCA) infarction with and without intravenous recombinant-tissue-plasminogen activator (rtPA) treatment. Methods: Patients with acute, large MCA infarction (National Institute of Health Stroke Scale [NIHSS] >15) who were treated during 2011-2014 were studied. The demographic data and the outcomes were compared between patients with and without intravenous rtPA treatment. Results: Two hundred and forty patients were included. Mean NIHSS score was 2o. One hundred and twenty patients were treated with intravenous rtPA treatment. The patients with rtPA treatment had higher rates of favorable outcomes ( $39 \%$ vs. $17 \%, P<0.001)$ and lower mortality rate $(16 \%$ vs. $51 \%, P<0.001)$. There was no significant difference in the occurrence of symptomatic intracerebral hemorrhage $(6 \%$ vs. $4 \%, P=0.715)$. Conclusions: The study showed the benefit and safety of intravenous rtPA treatment in patients with acute large MCA infarct.
\end{abstract}

Key words: Asia, middle cerebral artery, severe stroke, thrombolysis

\section{Introduction}

Intravenous thrombolysis is approved to treat eligible patients with acute ischemic stroke within $4.5 \mathrm{~h}$ of stroke onset. ${ }^{[1]}$ The increased odds of a favorable outcome are expected with the intravenous recombinant-tissue-plasminogen activator (rtPA). However, in the subgroup of patients with severe stroke, the benefit of intravenous rtPA is still debated. Many thrombolytic studies showed that severe stroke was associated with death and having symptomatic

\section{Address for correspondence:}

Dr. Pornpatr A. Dharmasaroja, Department of Internal Medicine

Division of Neurology, Faculty of Medicine,

Thammasat University, Klong 1,

Klong Luang, Pathumthani 12120, Thailand.

E-mail: pornpatr1@hotmail.com

\begin{tabular}{|l|l|}
\hline \multicolumn{2}{|c|}{ Access this article online } \\
\hline Quick Response Code: & Website: \\
\hline & www.ruralneuropractice.com \\
\cline { 2 - 3 } & \\
\hline & DOI: \\
\hline
\end{tabular}

intracerebral hemorrhage and inversely related to a favorable outcome. ${ }^{[2-5]}$ Major artery occlusion is usually found in patients with severe stroke. Intravenous rtPA is able to recanalize in approximate $1 / 3$ of the patients. ${ }^{[6]}$ This may explain the limited efficacy in these patients. Recently, studies of the combination of rapid endovascular therapy and intravenous thrombolysis showed the increased rate of recanalization and the improvement of clinical outcomes in patients with acute stroke from major artery occlusion. ${ }^{[7-9]}$ However, endovascular treatment requires more organized system of stroke care, health care personnel with special expertise, interventionists $24 / 7$ and also advanced neuroimaging capabilities, including cerebral angiography, which are available in only comprehensive stroke centers.

This is an open access article distributed under the terms of the Creative Commons Attribution-NonCommercial-ShareAlike 3.0 License, which allows others to remix, tweak, and build upon the work non-commercially, as long as the author is credited and the new creations are licensed under the identical terms.

For reprints contact: reprints@medknow.com

How to cite this article: Dharmasaroja PA, Muengtaweepongsa S. Outcomes of patients with large middle cerebral artery infarct treated with and without intravenous thrombolysis. J Neurosci Rural Pract 2016;7:36-9. 
Since intravenous rtPA treatment is approved in many countries, it is unethical to do the randomized controlled trial to see the benefit of this treatment over the placebo in patients with acute severe stroke. The purpose of this study is to retrospectively compare the outcomes of patients with acute large middle cerebral artery (MCA) infarction with and without intravenous rtPA treatment.

\section{Methods}

This is a retrospective, case-controlled study. Patients with acute large middle cerebral artery infarction who were treated at Thammasat University Hospital during January 2011 - May 2014 were studied. Inclusion criteria were a severe stroke (National Institute of Health Stroke Scale [NIHSS] score of at least 15), clinical deficits suggestive of large infarction in the territory of the MCA (such as gaze preference, aphasia, and neglect), and presentation within $24 \mathrm{~h}$ after stroke onset. All patients were treated following the standard care protocol. Thrombolysis was given in eligible patients who presented within $4.5 \mathrm{~h}$ and had no exclusion criteria for intravenous rtPA treatment. All patients were admitted and treated at the stroke unit with an experienced multidisciplinary stroke care team. Computed tomography (CT) of the brain was performed at baseline, when patients deteriorated and before starting anticoagulant.

Data about baseline characteristics of the patients, the course of diseases, stroke subtypes, neuroimaging, treatments, complications, and outcomes were retrospectively and prospectively collected. Stroke subtypes were classified by TOAST (Trial of ORG 10172 in Acute Stroke Treatment) criteria: Large-artery atherosclerosis, cardioembolic, small artery occlusion, a stroke of other determined cause, and stroke of undetermined cause (UND). A hemorrhage was considered symptomatic (according to ECASS study criteria) if it had not been identified on a previous CT scan, and there had subsequently been a decline in the neurological status of the patient (NIHSS $>4$ ). ${ }^{[10]}$ Clinical outcomes were evaluated by using modified Rankin scale (mRS). Favorable outcomes of the patients were defined by having mRS 0-2. All patients were follow-up at 3 and 6 months. If the patients were unable to come to follow-up at an outpatient clinic, they were called by a well-trained research assistant to assess clinical outcomes (mRS) and complications.

The data were presented as a mean or a median for continuous variables and percentage (number) for dichotomous variables. The demographic data, vascular risk factors and the outcomes of interest; favorable outcome, death, and symptomatic intracerebral hemorrhage, were compared between patients with and without intravenous rtPA treatment, using Student's $t$-test (for the continuous variables) and the Chi-square test (for the proportions). The research protocol was approved by the Human Ethics Committee of Faculty of Medicine, Thammasat University.

\section{Results}

Two-hundred and forty patients were included. Large MCA infarct counted for $13 \%$ of all acute ischemic stroke cases in our center. The mean age of the patients was 67. Mean NIHSS score was 20. Baseline characteristics of the patients are presented in Table 1. One hundred and twenty patients were not treated with intravenous thrombolysis. Reasons for not treating with thrombolysis were: Delay in arrival (28.9\%), large early hypodensity lesions in CT brain $(44.7 \%)$, too severe stroke $(5.3 \%)$, and others (21.1\%: Seizure, previous status [bed ridden], hemorrhagic transformation, or a combination of several reasons).

Patients without rtPA treatment had more history of old ischemic stroke, more proportion of UND stroke subtype, and came to the hospital later than those with the rtPA treatment [Table 2 and Figure 1]. Mean onset-to-needle time in the subgroup of patients received rtPA treatment was $177 \mathrm{~min}$. Symptomatic

\begin{tabular}{lc} 
Table 1: Baseline characteristics of the patients with \\
large MCA infarction \\
\hline Baseline characteristics & Total 240 cases \\
\hline Mean age (years, range) & $67(18-96)$ \\
Female $n(\%)$ & $111(46)$ \\
Mean NIHSS (years, range) & $20(15-30)$ \\
Hypertension $n(\%)$ & $151(63)$ \\
Diabetes mellitus $n(\%)$ & $52(22)$ \\
Hyperlipidemia $n(\%)$ & $85(35)$ \\
Coronary artery diseases $n(\%)$ & $37(15)$ \\
Old ischemic stroke $n(\%)$ & $46(19)$ \\
Transient ischemic attack $n(\%)$ & $3(1)$ \\
Smoking $n(\%)$ & $60(25)$ \\
Atrial fibrillation $n(\%)$ & $101(42)$ \\
Stroke subtypes & \\
LAA & $101(42)$ \\
CE & $98(41)$ \\
UND & $40(17)$ \\
OC & $1(0.4)$ \\
\hline
\end{tabular}

${ }^{*}$ NIHSS: National Institute of Health Stroke Scale, LAA: Large-artery atherosclerosis, CE: Cardioembolism, UND: Undetermined causes, OC: Other defined cause, MCA: Middle cerebral artery 
intracerebral hemorrhage occurred in $6 \%$ and $4 \%$ of the patients with and without rtPA, respectively. Seventy-six percentage of the patients were assessed for $\mathrm{mRS}$ at an outpatient clinic. At final follow-up (average 6 months), 17 patients missed follow-up (5 in no rtPA arm and 12 in rtPA arm) and were unable to be contacted in any way. Patients with intravenous rtPA treatment had higher rates of favorable outcomes $(39 \%$ vs. $17 \%, P<0.001)$ and lower death rate $(16 \%$ vs. $51 \%$, $P<0.001)$.

Table 2: Baseline characteristics and outcomes of the patients with acute MCA infarction treated with and without intravenous rtPA treatment

\begin{tabular}{|c|c|c|c|}
\hline \multirow[t]{2}{*}{ Baseline characteristics } & \multicolumn{2}{|c|}{$\begin{array}{l}\text { rtPA treatment } \\
(n=120)\end{array}$} & \multirow[t]{2}{*}{$P$} \\
\hline & No & Yes & \\
\hline Mean age (years) & 68 & 66 & 0.374 \\
\hline Mean NIHSS & 20 & 20 & 0.720 \\
\hline \multicolumn{4}{|l|}{$\operatorname{Sex} n(\%)$} \\
\hline Female & $60(50)$ & $48(40)$ & 0.251 \\
\hline Male & $60(50)$ & $72(60)$ & \\
\hline Hypertension $n(\%)$ & $78(65)$ & $73(61)$ & 0.504 \\
\hline Diabetes mellitus $n(\%)$ & $28(23)$ & $24(20)$ & 0.531 \\
\hline Hyperlipidemia $n(\%)$ & $49(41)$ & $36(30)$ & 0.079 \\
\hline Coronary artery diseases $n(\%)$ & $18(15)$ & $19(16)$ & 0.605 \\
\hline Old ischemic stroke $n(\%)$ & $34(28)$ & $13(11)$ & 0.001 \\
\hline Smoking $n(\%)$ & $32(27)$ & $28(23)$ & 0.551 \\
\hline Atrial fibrillation $n(\%)$ & $53(44)$ & $48(40)$ & 0.478 \\
\hline \multicolumn{4}{|l|}{ Stroke subtypes } \\
\hline LAA & $42(35)$ & $59(49)$ & \\
\hline CE & $49(41)$ & $49(41)$ & \\
\hline UND & $28(23)$ & $12(10)$ & \\
\hline $\mathrm{OC}$ & $1(1)$ & 0 & 0.016 \\
\hline Mean ASPECTS* & 4.78 & 7.45 & $<0.001$ \\
\hline Hyperdense MCA sign $n(\%)$ & $38(32)$ & $36(30)$ & 0.832 \\
\hline Mean blood sugar (mg/dL) & 136 & 134 & 0.899 \\
\hline Mean onset-to-hospital time (min) & 321 & 133 & $<0.001$ \\
\hline Symptomatic intracerebral hemorrhage $n(\%)$ & $5(4)$ & $7(6)$ & 0.715 \\
\hline Decompressive surgery $n(\%)$ & $23(19)$ & $14(12)$ & 0.090 \\
\hline Favorable outcome $n(\%)$ & $19(17)$ & $42(39)$ & $<0.001$ \\
\hline Death $n(\%)$ & $59(51)$ & $17(16)$ & $<0.001$ \\
\hline
\end{tabular}

\section{Discussion}

Prognosis of patients with large MCA infarct is poor, with case fatality rates in previous intensive care-based series of nearly $80 \%{ }^{[11,12]}$ In the modern era, which several recanalization therapies were applied at the very early onset of stroke, the prognosis of these patients would be better. Intravenous rtPA treatment increases the proportion of favorable outcomes in patients with acute ischemic stroke by a third. Several factors had been studied to predict the favorable outcomes in patients who were treated with intravenous rtPA. Severe stroke was usually found as a poor prognostic factor. ${ }^{[2-5]}$ A previous study in Thai, unselected patients with acute ischemic stroke who received rtPA treatment did show the higher rate of favorable outcome (mRS 0-1;47\%) than our study. ${ }^{[4]}$ In that study, severe stroke (NIHSS > 15) was inversely related to favorable outcome (odds ratio [OR]: 0.193, 95\% confidence interval [CI]: 0.084-0.442, $P<0.001)$ and associated with death (OR: 5.895, 95\% CI: 1.2594-26.850, $P=0.022$ ).

Since the approval of intravenous rtPA treatment, there was no prospective, randomized controlled trials directly compare the benefit of rtPA treatment versus the placebo in patients with severe stroke. The third international stroke trial (IST-3), which is the largest study of thrombolysis, compared the efficacy, and safety of intravenous rtPA versus placebo in the $0-6 \mathrm{~h}$ time window, in patients who were not eligible for thrombolysis according to the license. ${ }^{[13,14]}$ Although it was not designed to look for the effect of stroke severity on the outcome, subgroup analysis showed that patients with severe stroke (NIHSS > 15) who received intravenous rtPA had a higher proportion of favorable outcomes (21\%) as compared to the control group (9\%)..$^{[14]}$

Our study compared the outcomes of the patients with acute, large MCA infarct after intravenous rtPA treatment with no rtPA treatment. The patients with rtPA treatment had higher rates of favorable outcomes ( $39 \%$ vs. $17 \%, P<0.001$ ) and lower rate of mortality ( $16 \%$ vs. $51 \%, P<0.001)$. There was no significant difference in the occurrence of symptomatic

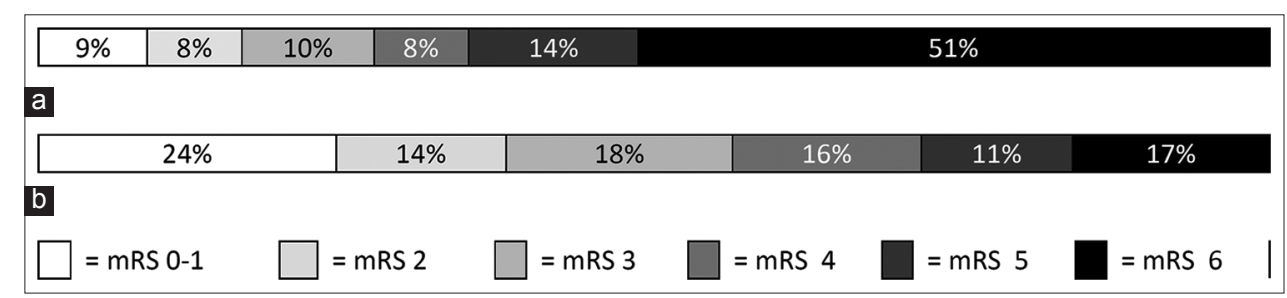

Figure 1: Outcomes of patients with large middle cerebral infarction (a) modified Rankin scale in no recombinant-tissue-plasminogen activator treatment arm, (b) modified Rankin scale in recombinant-tissue-plasminogen activator treatment arm 
intracerebral hemorrhage ( $6 \%$ vs. $4 \%, P=0.715$ ). However, this was a retrospective study, and there were a few differences in baseline characteristics between 2 groups. Patients without rtPA treatment had more history of old ischemic stroke, more proportion of UND stroke subtype and came later than those with the treatment. Most patients, who were classified as UND, had large-artery occlusion and also cardiac causes of stroke. Accompanying cardiac diseases could interfere with rehabilitation process and recovery. This might partly explain the lower rates of favorable outcomes.

Patients with severe stroke (NIHSS $>10$ ) have a $>80 \%$ likelihood of having a major arterial occlusion. ${ }^{15]}$ Recanalization rates within $24 \mathrm{~h}$ after the administration of intravenous rtPA are low, when occlusion involves large intracranial arteries, with the rate of $14 \%$ for internal carotid arteries and $30-55 \%$ for middle cerebral arteries. ${ }^{[6,16]}$ This may explain the limited efficacy in these patients. The combination of rapid endovascular treatments and intravenous thrombolysis has recently shown a higher rate of recanalization and clinical benefit as compared to standard treatment or intravenous thrombolysis alone..$^{[7-9]}$ However, most of the positive trials include the selected patients with small infarct core and rather good collateral circulation, and endovascular treatment needs to be done rapidly (median time from stroke onset to groin puncture range from 185 to $260 \mathrm{~min}$ ). ${ }^{[7-9]}$ EXTEND-IA study used the perfusion imaging criteria in selection the included patients which approximately $25 \%$ clinical eligible patients with vessel occlusion were excluded on the basis of this criteria. ${ }^{[9]}$ Endovascular treatment also requires organized system of stroke care, health care personnel with special expertise, interventionists $24 / 7$, and advanced neuroimaging capabilities which are available in only comprehensive stroke centers.

\section{Conclusions}

The study showed the benefit and safety of intravenous rtPA treatment in patients with acute large MCA infarct. Although this was a retrospective study, patients were included rather early as compared with previous studies. Eligible patients with severe MCA infarct should be treated with intravenous rtPA.

\section{Financial support and sponsorship}

This research is funded by Thammasat University.

\section{Conflicts of interest}

There are no conflicts of interest.

\section{References}

1. Jauch EC, Saver JL, Adams HP Jr, Bruno A, Connors JJ, Demaerschalk BM, et al. Guidelines for the early management of patients with acute ischemic stroke: A guideline for healthcare professionals from the American Heart Association/American Stroke Association. Stroke 2013;44:870-947.

2. Wahlgren N, Ahmed N, Eriksson N, Aichner F, Bluhmki E, Dávalos A, et al. Multivariable analysis of outcome predictors and adjustment of main outcome results to baseline data profile in randomized controlled trials: Safe implementation of thrombolysis in stroke-monitoring study (SITS-MOST). Stroke 2008;39:3316-22.

3. Demchuk AM, Tanne D, Hill MD, Kasner SE, Hanson S, Grond M, et al. Predictors of good outcome after intravenous tPA for acute ischemic stroke. Neurology 2001;57:474-80.

4. Dharmasaroja PA, Dharmasaroja P, Muengtaweepongsa S. Outcomes of Thai patients with acute ischemic stroke after intravenous thrombolysis. J Neurol Sci 2011;300:74-7.

5. Dharmasaroja PA, Muengtaweepongsa S, Pattaraarchachai J, Dharmasaroja P. Intracerebral hemorrhage following intravenous thrombolysis in Thai patients with acute ischemic stroke. J Clin Neurosci 2012;19:799-803.

6. Christou I, Burgin WS, Alexandrov AV, Grotta JC. Arterial status after intravenous TPA therapy for ischaemic stroke. A need for further interventions. Int Angiol 2001;20:208-13.

7. Berkhemer OA, Franse PS, Beumer D, Yeatts SD, Khatri P, Hill MD, et al. A randomized trial of intra-arterial treatment for acute ischemic stroke. N Engl J Med 2015;372:11-20.

8. Goyal M, Demchuk AM, Menon BK, Sqoifo A, Ponsio M, Sterzi R, et al. Randomized assessment of rapid endovascular treatment of ischemic stroke. N Engl J Med 2015;372:1019-30.

9. Campbell BC, Mitchell PJ, Kleinig TJ, Dewey HM, Churilov L, Yassi N, et al. Endovascular therapy for ischemic stroke with perfusion-imaging selection. N Engl J Med 2015;372:1009-18.

10. Hacke W, Kaste M, Fieschi C, von Kummer R, Davalos A, Meier D, et al. Randomised double-blind placebo-controlled trial of thrombolytic therapy with intravenous alteplase in acute ischaemic stroke (ECASS II). Second European-Australasian acute stroke study investigators. Lancet 1998;352:1245-51.

11. Hacke W, Schwab S, Horn M, Spranger M, De Georgia M, von Kummer R. 'Malignant' middle cerebral artery territory infarction: Clinical course and prognostic signs. Arch Neurol 1996;53:309-15.

12. Berrouschot J, Sterker M, Bettin S, Köster J, Schneider D. Mortality of space-occupying ('malignant') middle cerebral artery infarction under conservative intensive care. Intensive Care Med 1998;24:620-3.

13. Leys D, Cordonnier C. rt-PA for ischaemic stroke: What will the next question be? Lancet 2012;379:2320-1.

14. IST- collaborative group, Sandercock P, Wardlaw JM, Lindley RI, Dennis M, Cohen G, et al. The benefits and harms of intravenous thrombolysis with recombinant tissue plasminogen activator within $6 \mathrm{~h}$ of acute ischaemic stroke (the third international stroke trial [IST-3]): A randomised controlled trial. Lancet 2012;379:2352-63.

15. Fischer U, Arnold M, Nedeltchev K, Brekenfeld C, Ballinari P, Remonda L, et al. NIHSS score and arteriographic findings in acute ischemic stroke. Stroke 2005;36:2121-5.

16. Rha JH, Saver JL. The impact of recanalization on ischemic stroke outcome: A meta-analysis. Stroke 2007;38:967-73. 